\title{
Geography education by the combination use of GIS and AR - Practices in National Institution of Technology, Toyama College-
}

\author{
Koji OHNISHI ${ }^{\mathrm{a},}$, , Hiroaki AKIMOTO ${ }^{\mathrm{b}}$, Yoshihiro UGAWA ${ }^{\mathrm{c},}$ Satoru ITOH $^{\mathrm{d}}$ \\ ${ }^{a}$ University of Toyama,ohnishik@hmt.u-toyama.ac.jp, ${ }^{b}$ Dokkyo University,hakimoto@dokkyo.ac.jp \\ ${ }^{c}$ Miyagi University of Education, ugawa@staff.miyakyo-u.ac.jp, ${ }^{d}$ KanazawaUniversity, itoh@ed.kanazawa-u.ac.jp \\ * Corresponding author
}

Keywords: Geography Education, Reading Maps, Topographical Map, Landscape

\begin{abstract}
:
AR technology on the landscape is useful for people to identify the places with air tags. There are many people who cannot match landscapes and maps. For Map reading skill building, AR supports for people to match the landscape and maps. This paper tried to measure the effectiveness of AR technology to map reading skill building in high school geography education.
\end{abstract}

In Japan, Geography will be compulsory subject from high school from 2022. The compulsory Geography as school subject has three themes, 1 Maps and GIS, 2 International understandings and International Corporation, 3 Disaster prevention and ESD. Maps and GIS are fundamental skills for learning geography. Map reading is very important and there are several researches of the geography classes with paper maps, especially topographical maps (Ito, 2005). GIS education is also important for students to understand how to use the maps (Tani etal., 2002). In Japan, there are few high schools and teachers to use GIS on geography class. With curriculum reformation, every student will have to learn GIS, and teachers will have to teach GIS in the geography class, too. It is big problem.

Students learn topographical map reading technique on geography class as indoor activity. There are few activities to match the real landscape and topographical map. This skill is important for student to understand the map function and meaning of landscape. Fieldwork education is not popular among schools. Teachers have poor skills to do it. AR could build up the lessons to combine GIS, map and fieldwork education. It is not easy to match the topographical map and landscape. AR technology supports for students to do the tasks. The aim of this paper to check the effectiveness of AR support for map readings. We did three periods geography experimental classes in National Institution of Technology, Toyama College $1^{\text {st }}$ grade. $1^{\text {st }}$ period class content was physical geography especially on coastal geomorphology. $2^{\text {nd }}$ period was understanding the lagoon with topographical map (Fig. 1). $3^{\text {rd }}$ period was topographical map and landscape with AR.

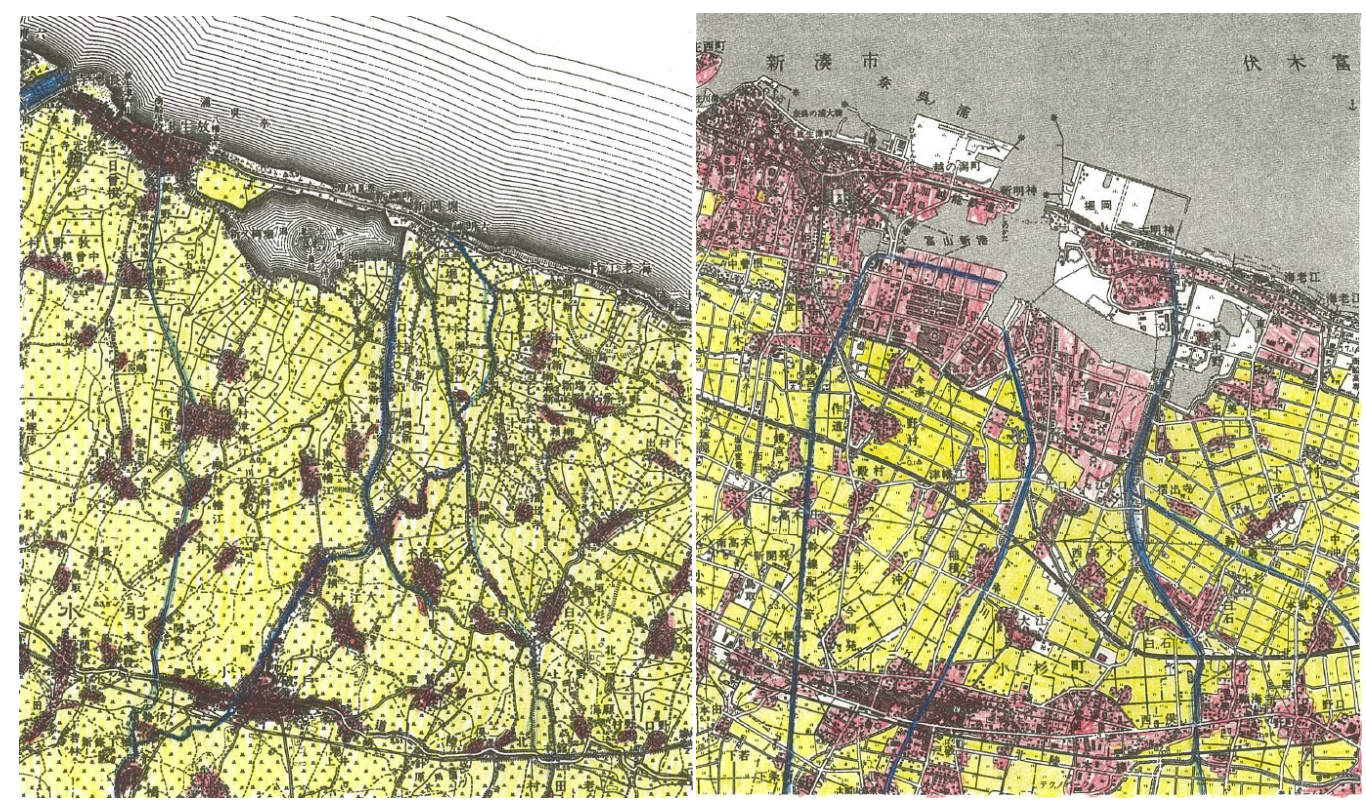

Fig.1 Topographical maps and changes of lagoon (Left in 1910, Right in 1996 around school) 


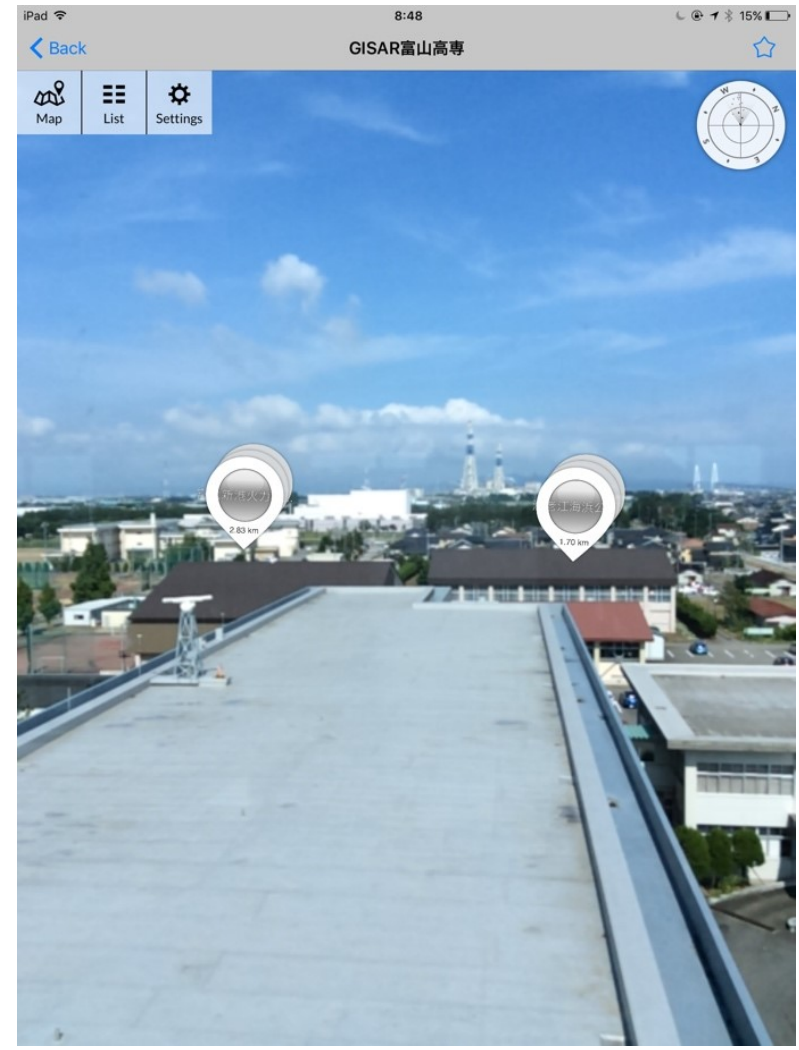

Fig.2 AR with air tags

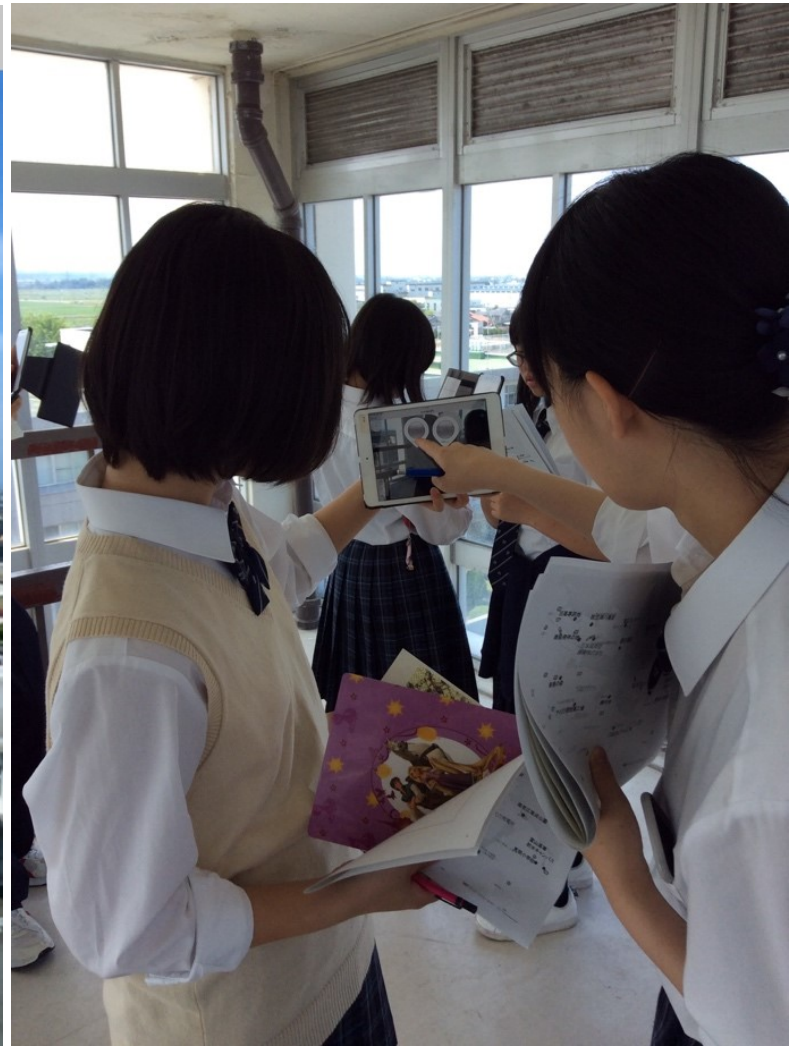

Fig.3 Students activities with tablet

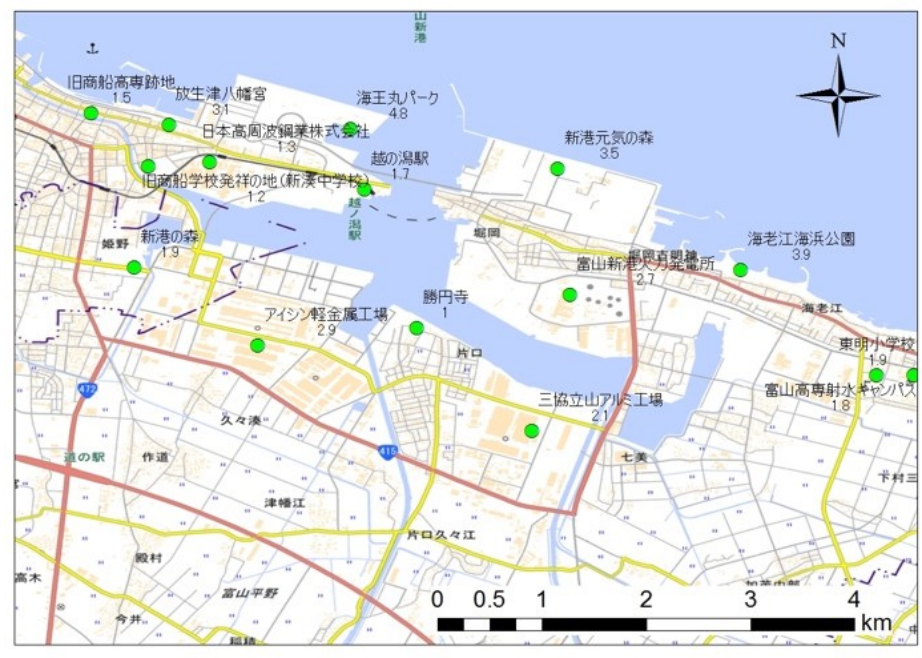

Fig.4 Maps as worksheet (GSI Map)

In the 3rd period practice, they used tablet and smartphone to identify the landscape. They watched the landscape with air tags (Fig.2), and they tried to match the landscape and map (Fig.3). Students checked the worksheet and maps on the activities (Fig.4).

Students understood how to match the landscape and maps with AR air tags. It is adequate tasks for students to understand how to match between landscape and maps. They did these tasks in this class and they became to do it with no difficulties.

There were several technological problems. Digital compass is not accurate when the tablets were started. We should adjust the compass before the class. Next problem is air tags. If the tags are on same direction, the tags are overlapped. There problems are easy to get over. With this trial class, topographical maps and landscape education with GIS with AR is effective for students. Maps education with Geographical Information technology has important role for next generation. We should make textbook for teachers to do this method.

This work was supported by JSPS KAKENHI Grant Number 16H03520 